\title{
LOAD SHEDDINGTECHNIQUES FOR SYSTEM WITH COGENERATION: A REVIEW
}

\author{
Pradeepti Lakra and Mukesh Kirar \\ Department of Electrical Engineering, M.A.N.I.T., Bhopal, India
}

\begin{abstract}
In developing countries a large demand of power will be seen in future. It is essential to maintain power continuity and reliability. Contingencies like fault occurrence and generated power and load demand imbalance causes system frequency instability. Load-shedding is the ultimate solution to restore system frequency and ensure availability of electrical power to critical loads in the plant. This paper presents a review of traditional adaptive and computational intelligent load shedding scheme. A comparison of these entire schemes with corresponding advantages and disadvantages is summarized.
\end{abstract}

\section{KEYWORDS}

Under frequency; contingency; critical load; load shedding

\section{INTRODUCTION}

Reliable and secure operation of large power systems is the primary goal for system operators [2]. Industrial plants are prone to short-circuits, generation loss and sudden breakdown of distribution lines. These cause load imbalance which can lead to frequency decay, initial power deficiency, dangerous cascade effects, or even shutdown of one or more generators. Blackouts affect utilities, ships, refineries, mines, industrial processes and almost every power system in the world [5]. In order to prevent these events, various Load Shedding (LS) strategies are adopted to restore the generated and absorbed power balance [1, 7]. Basically, a load shedding scheme acts whenever it diagnoses a situation of danger for the system. A historical method for detecting power unbalances is to detect a fall or rise in the frequency of the power system $[2,10]$. The threshold value of underfrequency (UF) or overfrequency (OF) is used as a triggering for shedding of loads or generators so that the power system stability can be maintained [7, 11]. Therefore, both underfrequency and overfrequency condition should also be prevented [5]. While load variations are considered as disturbances, LS algorithm must

Detect power deficiency and compute minimum load power to be removed using available spinning reserve [31]. Every power system has its own under frequency load shedding (UFLS) plan. A UFLS plan must be reliable, simple, efficient, fast, robust and properly coordinated with the neighboring power system [9].

This paper presents a review of load shedding schemes to restore load generation balance and keep system frequency within permissible limits. Therefore Load shedding helps to maintain the power system stability and reliability. 


\section{SYSTEM FREQUENCY RESPONSE}

Power system frequency falls down rapidly if mismatch occurs between generation and the load demand in case a power disturbance occurs. [21]. Off-normal frequency can directly affect power system operation and reliability. A large frequency deviation can damage connected equipments, degrade load performance, cause transmission line overloading and can interfere with various protection schemes, ultimately causing system collapse in severe cases [1, 3, 24]. Depending on the frequency deviation range, supplementary control such as load-frequency control (LFC) and emergency control may be required in addition to the natural governor response [24]. Power plant auxiliary services are more sensitive in terms of minimum allowable frequency. They begin to malfunction at a frequency of $47.5 \mathrm{~Hz}$. At frequency of about $44-46 \mathrm{~Hz}$ the asynchronous motors of the auxiliary services are disconnected by their protections [2, 33]. The steam turbines are more sensitive to frequency drops and can sustain up to 10 contingencies at $47.5 \mathrm{~Hz}$ for one second. Hence frequency fall below $47.5 \mathrm{~Hz}$ should be avoided [2]. On occurance of a disturbance, frequency of generators depends on following factors.

- The generator closer to the disturbance location show a faster rate of initial frequency decay $[2,6,8,21]$.

- Generators with higher inertia constant have lower rate of frequency decline and less frequency decline [11, 34].

- Load damping factor is an important parameter in the settling system frequency following a disturbance. However, it has no significant effect on the initial frequency behavior of generator after a disturbance [8].

Hence, for minimum frequency deviations factors $[8,32,34]$ are discussed in Figure 1 . The values of the minimum frequency and the new steady-state frequency reached during the transient process are proportional to the power imbalance and depend on the dynamic properties of turbines, governors, loads, and other control devices [10].

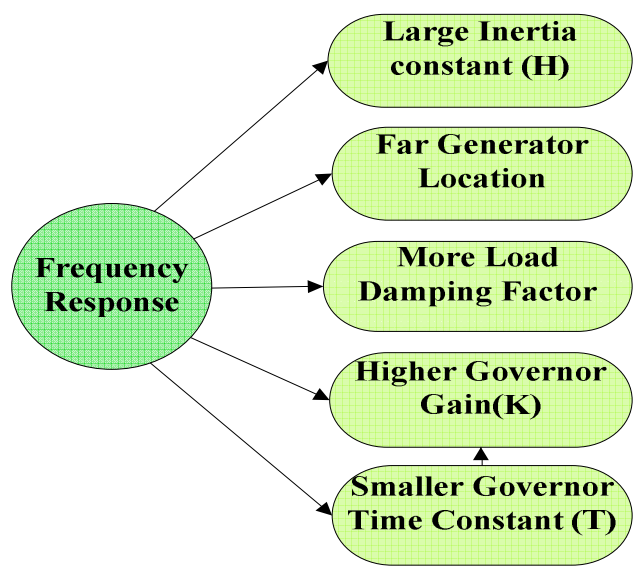

Figure1. Ideal Factors affecting frequency response of generators

\section{CLASSIFICATION OF LOAD SHEDDING SCHEMES}

Different authors have given various loads shedding classification. Uchhrang K. Jethwa along with his team in [13] has classified LS as cause-based scheme and effect-based scheme of load- 
shedding $[13,14]$. The overall load-shedding has been grouped as Primary load shedding: based on the generation deficit calculations and Slow load shedding: based on overloading of power system equipment [13]. According to M. Giroletti, M. Farina and R. Scattolini in [1] basically, load shedding can be done based on load or based on frequency.

\subsection{Power-based load shedding (PLS)}

It computes power deficiency and load power to be removed based on the instantaneous measurements.

\subsection{Frequency-based load shedding (FLS)}

It monitors frequency and its derivative at specified thresholds.

In order to overcome the main drawbacks of the PLS and FLS, hybrid load shedding (HLS) algorithm is proposed [1] which combines the significant features of above mentioned approaches i.e. robustness, unresponsive to measurement delays and the use the updated spinning reserve. The mismatch detection is performed by analyzing $\Delta d f(t) / \Delta d t$ [6]. B. Delfino in [2] has classified load shedding scheme as traditional, semi-adaptive and adaptive.

\subsection{The traditional load shedding}

It is simplest and cheep method. The traditional scheme sheds a fixed amount of the load in case of frequency fall below specified threshold [2].

\subsection{The semi-adaptive scheme [21]}

In this method Load is shed by measuring $d f / d t$ if frequency threshold is reached.

\subsection{The adaptive method}

It employs the system frequency response model.

This paper classifies load shedding as Conventional, Adaptive and computational intelligent load shedding schemes as shown in Figure 2.

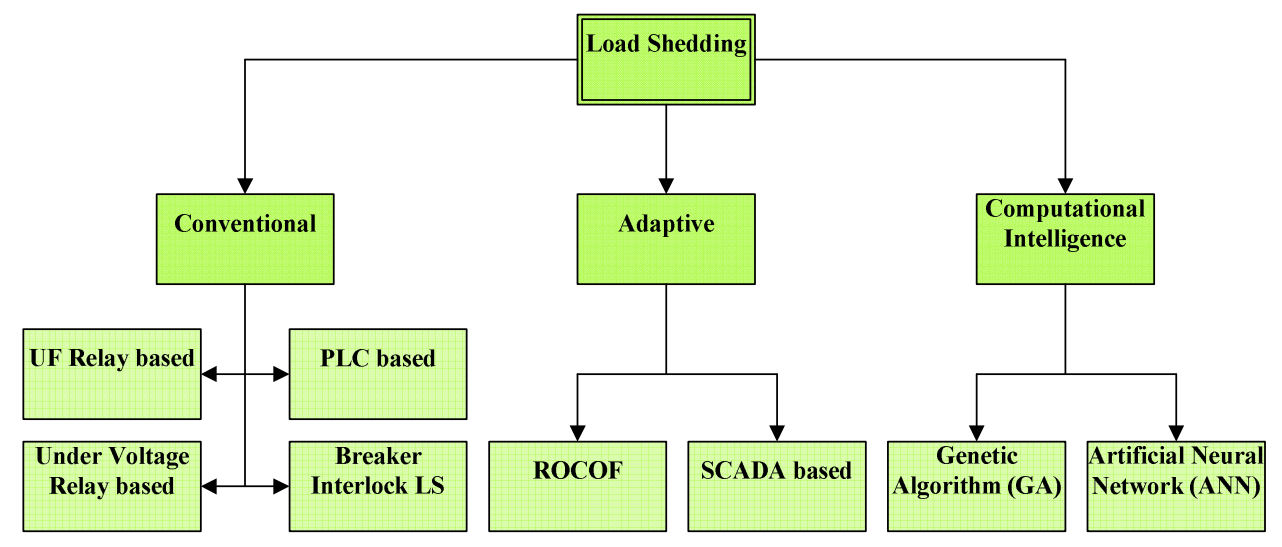

Figure 2. Classification of Load Shedding Techniques 


\section{LOAD SHEDDING TECHNIQUES AND THEIR TYPES}

Small frequency deviations are automatically restored by governor natural response (primary control) [6,7], while for larger frequency deviations, emergency control and protection schemes are required $[21,34]$. The load shedding scheme should be quick, reliable, avoid unnecessary actions and shed a minimum amount of load [2,33]. The main types of load shedding schemes are as below:

\subsection{The traditional or conventional load shedding}

The traditional scheme sheds a predefined amount of the load corresponding to fixed preset values of frequency $[2,5]$. These values of the thresholds are decided off-line, on the basis of experience and simulations $[9,35]$.

\subsubsection{Under frequency load shedding relays}

Power plants are subjected to failure at low frequencies. If governor actions cannot activate spinning reserve quickly to restore the normal operating frequency, protective frequency relays trip generation units [36-39]. Under frequency load shedding relays are employed to prevent tripping of the generation units [5]. This scheme [5] involves formation of a contingency list according to worst possible impacts causing severe power imbalance. All the required data such as relays, Circuit breakers, corresponding time delays, operational frequency value, and the priority list of loads are specified by the user. Under frequency relay based load shedding is designed in [36] as below.

a) Maximum possible overload:

$$
L=\frac{P_{T D}-P_{G}}{P_{G}}
$$

Where, $\mathrm{L}$ : anticipated overload factor

$\mathrm{P}_{\mathrm{TD}}, \mathrm{P}_{\mathrm{G}}$ : Total Demand, Total Generation

b) Load shed amount:

$$
L S=\frac{\frac{L}{1+L}-d\left(1-\frac{f}{f_{0}}\right)}{1-d\left(1-\frac{f}{f_{0}}\right)}
$$

Where, L : per unit overload

$f:$ Minimum permissible frequency

$d$ : Load reduction factor

$f_{0}$ : Nominal frequency

c) Relay settings:

The UFLS relay is initialized to shed a fixed amount of load in predefined 3-5 steps when frequency falls below a certain predefined threshold in order to prevent a blackout $[36,37]$.

Under frequency relay based load shedding was tested on a commercial power system in [2] with total load under relief of $1000 \mathrm{MW}$ i.e. about $30 \%$ of active load of the system. The relay delay time was set to $0.1 \mathrm{~s}$, which is most common. Table 1 . Shows the corresponding load shedding result of the schemes[2]. However they have some drawbacks [16] as described below. 
- The scheme incorporates time delay. Due to time taken by the frequency to reach the predefined settings. These time delays as a sum result into a slow response [5].

- Usually setting of each frequency relay is based on the most severe disturbance conditions, so incorrect loadshedding may take place [16].

- Frequency relay settings require simulation of hundreds of transient stability studies which are not actually dependent on the real time operating conditions [16].

Table 3. Relay setting

\begin{tabular}{|l|l|l|l|}
\hline $\begin{array}{l}\text { Traditional } \\
\text { under } \\
\text { frequency relay } \\
\text { based load } \\
\text { shedding }\end{array}$ & $\begin{array}{l}\text { Frequency } \\
\text { threshold }\end{array}$ & $\begin{array}{l}\text { \%load } \\
\text { shed }\end{array}$ & $\begin{array}{l}\text { Time } \\
\text { delay }\end{array}$ \\
\hline Step 1 & $49.58 \mathrm{~Hz}$ & $40 \%$ & $0.1 \mathrm{sec}$ \\
\hline Step 2 & $49 \mathrm{~Hz}$ & $30 \%$ & $0.1 \mathrm{sec}$ \\
\hline Step 3 & $48.3 \mathrm{~Hz}$ & $30 \%$ & $0.1 \mathrm{sec}$ \\
\hline
\end{tabular}

\subsubsection{Under voltage relay based load shedding}

When a fault takes place, within 1-2 seconds, the system voltage drops much faster than frequency decays [38]. Undervoltage protection schemes as per voltage tolerance curves (according to past data) of the critical loads [9] are employed to save in-plant loads and cogeneration units of an industrial system [41]. Time delay setting of undervoltage relays should minimum for easy activation [9,39]. A fault contingency and the residual voltage of the cogeneration units can be calculated by short circuit analysis. Transient stability analysis calculates time delays using the critical clear time (CCT) of the cogeneration system [39-40]. As the undervoltage relays can can easily be activated by even small voltage disturbance $[9,39]$. This is a drawback of undervoltage relay based load shedding. 


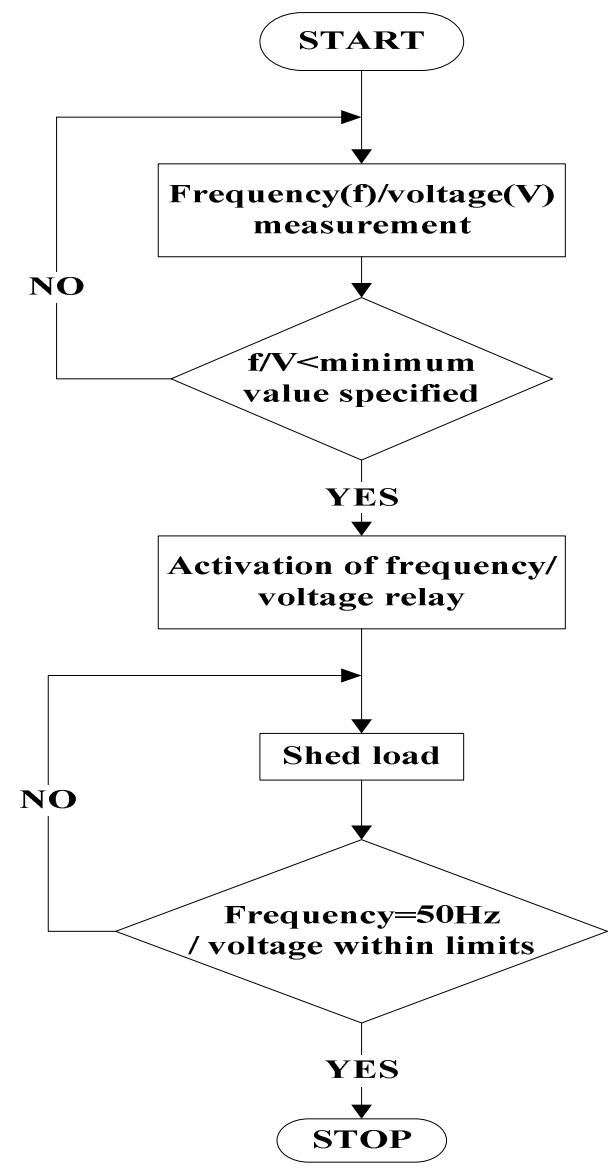

Figure 3. Flow chart for under frequency and under voltage relay based load shedding

\subsubsection{Programmable Logic Controller-Based Load Shedding}

Programmable logic controller is programmed at substations to initiate a trip signal to the appropriate feeder breakers. Programming is based on the number of generators, total amount of load, and the underfrequency conditions [42-43]. It involves continuous monitoring of circuit breaker positions, generator status, and overall power flows in the system. Possible contingencies are evaluated, and required load shedding is assembled [42]. However, this table is independent of any changes that may take place in the system [16, 42]. PLC systems are faster and accurate than underfrequency relays [16]. However, PLC systems, uses underfrequency relays as a backup [16] due to reasons such as:

- The processing time in PLC leads to slow response of load shedding.

- The monitoring is confined to a portion of the network.

- Some sequence of events may occur that are not programmed into the PLC, resulting in load shedding failure.

Despite its added complexity and cost, the PLC load-shedding system is preferred because of its speed of response and its ability to handle changing power system conditions [25]. 


\subsubsection{Breaker Interlock Load Shedding}

This is the simplest method of load shedding used when speed of LS is critical. The circuit breakers are linked to a set of load circuit breakers to trip [16]. Any power disturbance automatically sends a fast signals to the load breakers to open. Absence of processing in this scheme gives a fast response without any intentional time delay. Despite fast execution this scheme possesses a number of inherent drawbacks as below [16, 26]:

- Load shedding is based on worst conditions thus changing load priority is difficult.

- Only one stage of load shedding that can completely shut down the entire system.

- Unnecessary load shed than required because breaker interlock list is preselected without knowledge of system transient response

- Modifications to the system are costly

\subsection{The adaptive scheme for load shedding}

Conventional load-shedding strategies perform well in electrical system distributed on geographical bases, but not in industrial systems [6, 7]. UFLS very often disconnects more or less load than is required. This causes undesired damages and serious costs [10]. No traditional schemes take into account load-level changes, system inertia changes, changes in load composition, governor response characteristics, or changes in system topology [11]. In adaptive UFLS (AUFLS) these parameters are included and magnitude of disturbance is estimated online $[7,10]$. This method is based on real time topology and communicates between remote protective relays and centralized UF appliance [10,11]. The inertia compensation and load tracking system (ICLT) communicates directly to the generator relays and sheddable load relays through MUX.

Hence operation from thousands of kilometers away is possible without any compromise in timing or performance [11].For the design of an AUFLS plan, The behavior of multi-machine electric power systems immediately after sudden load generation imbalance is initiated $[21,34]$.The disturbance location and initial slope seen by every relay along with inertia constant plan is designed using swing equation (3) [7,10].

Where,

$$
\left.\frac{d f}{d t}\right|_{t=0}=\frac{P_{\text {step }}}{2 H}
$$

$f:$ per unit $(50$ or $60 \mathrm{~Hz})$

$P_{\text {step }}:$ per unit on the total system MVA

From the estimated disturbance, number of steps, frequencies, time delays, and the amount of load to be disconnected from the network in every step is determined [10]. Load is shed in steps and not in one stroke which is an advantage to this scheme. A drawback of this scheme is that, the inertia changes of the system should be accordingly adapted [10].

\subsubsection{Rate of change of Frequency (ROCOF) based Load Shedding}

According to equation (3), the initial ROCOF following a disturbance is directly proportional to the power imbalance and also depends on the electric power system inertia [6,7]. The activepower deficit $\left(P_{d e f}\right)$ is dependent on initial mechanical power on turbines, active power consumption just before the disturbance, spinning reserve, turbine-governor reaction and the active power load change due to voltage and frequency deviation. For effective load-shedding, firstly load shedding amount should be minimum, as not more than $20 \%$ of spinning reserve can be obtained in first few seconds [7]. Secondly frequency trajectory should be within limits. This 
is done through partial shedding (Figure 4.). As first shedding stage $(f=47.5 \mathrm{~Hz})$ drastically changes the gradient and gives the turbine governor more time to react [12], only a part of $P_{t r i p}$ is to be shed in the first step (eg. 35\% of trip).

$$
\frac{d f_{k}}{d t}<0 \text { and } \frac{\frac{d f_{0}}{d t}|-| \frac{d f_{k}}{d t}}{\left|\frac{d f_{0}}{d t}\right|} .100 \geq A P(f) .
$$

Where, $\operatorname{AP}(f): \%$ Ptrip that should be shed until the $k_{t h}$ checkpoint

The frequency gradient measurement can give misleading information about the active power deficit load bus voltages and characteristics of connected load (factor $\alpha_{\mathrm{i}}$ ) are unknown [12]. Power deficit can be calculated using the system frequency response model $[6,19,44]$. The model is based on largest time constants such as generation unit inertia and reheats time constant in the generation units of the isolated system [6]. The major drawback of using the frequency-response model for UFLS [7]:

- The load's voltage dependence is not included in the model.

- The frequency gradient soon after the disturbance is measured with some time delay.

Table 2 describes a refinement to the emergency control protection schemes can be achieved by using $\Delta \mathrm{f} / \Delta \mathrm{t}$ settings rather than $\mathrm{df} / \mathrm{dt}$ settings [6].

Table 2

\begin{tabular}{|c|c|c|}
\hline & $d f / d t$ & $\Delta f / \Delta t$ \\
\hline Accuracy & More deviated values & Closer values \\
\hline $\begin{array}{c}\text { Other } \\
\text { Oscillations }\end{array}$ & Influence frequency & $\begin{array}{c}\text { No influence on } \\
\text { frequency }\end{array}$ \\
\hline LS Speed & Faster & Slower \\
\hline $\begin{array}{c}\text { Risk of fake } \\
\text { operation }\end{array}$ & More & Reduced \\
\hline
\end{tabular}

\subsubsection{SCADA Based Load Shedding}

To have a high reliability solutions, without any data transfer through communication links the SCADA system are preferred at UFLS [7]. Formal approach based on a finite state transition model [3] is introduced to define the load shedding actions for a medium/large industrial plant. Compared to the frequency based LS schemes, the response time is well within the power system requirements, no special relays or devices need to be installed and load unbalance calculation are much faster. LS scheme based on SCADA[8] is as below.

- Magnitude of disturbance is detected by collecting all generators rate of frequency decline.

- Critical overload is defined and SFR model is designed first.

- If the overload is more than the critical value, total load must be dropped with zero time delay. 
Electrical and Electronics Engineering: An International Journal (ELELIJ) Vol 4, No 3, August 2015

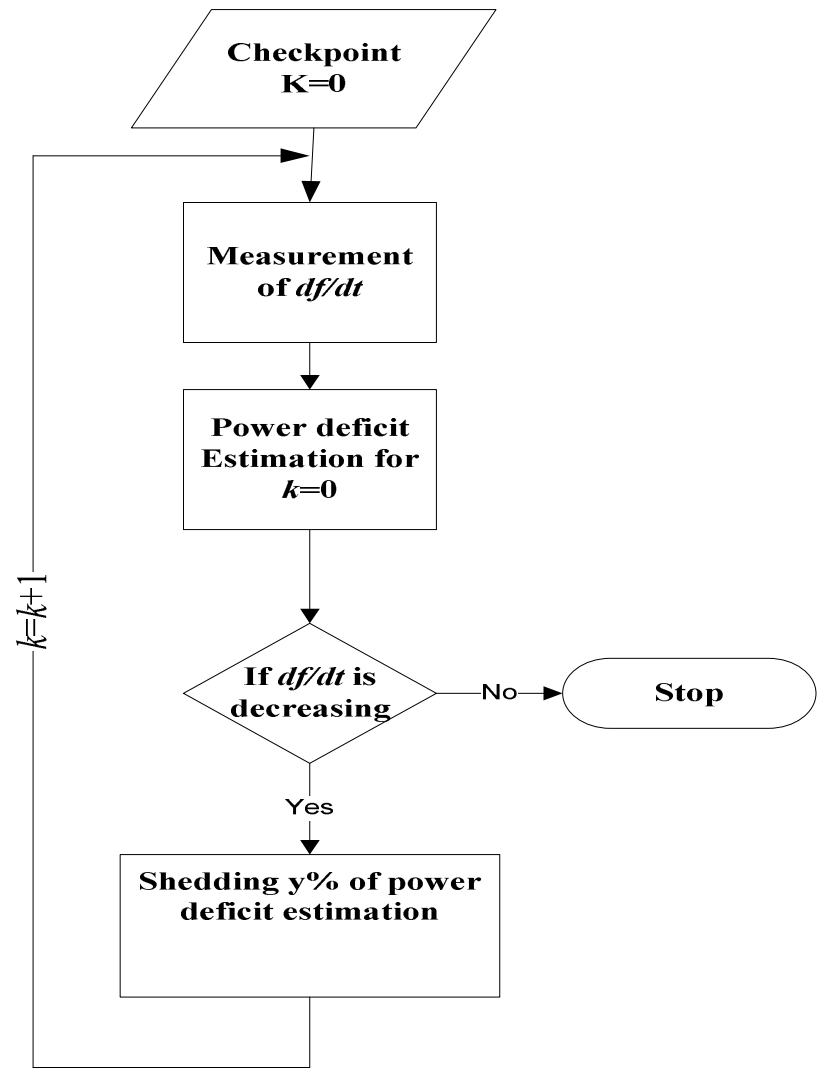

Figure 4. A flow chart for partial shedding of load w.r.t. $50 \mathrm{~Hz}$

$\mathrm{K}: 0,1,2 \ldots$.

$\mathrm{f}(\mathrm{k}): 49,48.8,48.4,47 \ldots . \mathrm{Hz}$

$\mathrm{y}(\mathrm{k}): 35,30,20,15 \%$

System status is defined by $\mathrm{CB}$ position. "bit=0", represent an open $\mathrm{CB}$ and "bit=1" a closed CB. The position of these circuit breakers is detected by SCADA [8]. If the frequency drops below a set value $\left(f_{\min }\right)$ for a time longer than $t_{\text {min }}$; the SCADA starts a step by step load-shedding with a fixed time cycle $\left(t_{c y c l e}\right)$. The process stops when the frequency rises above the threshold. SCADA based scheme overcomes the shortcomings of adaptive UFLS procedures and provides a fast and reliable operation [8].

\subsection{Computational Intelligent load shedding}

Even with advanced techniques to improve load shedding efficiency such as adaptive techniques the tripping signal that starts the LS phenomenon is always the frequency or its derivative [3]. These methods does not fit the requirements of industrial plants as Generating capacity varies widely, flexible Distribution network, high Frequency decay rate and small Number of load [5]. This scheme overcomes the drawbacks of previous two schemes. Fast load shedding based on real time operating conditions is possible with exact amount of load shed requirement. An intelligent load shedding 
Electrical and Electronics Engineering: An International Journal (ELELIJ) Vol 4, No 3, August 2015

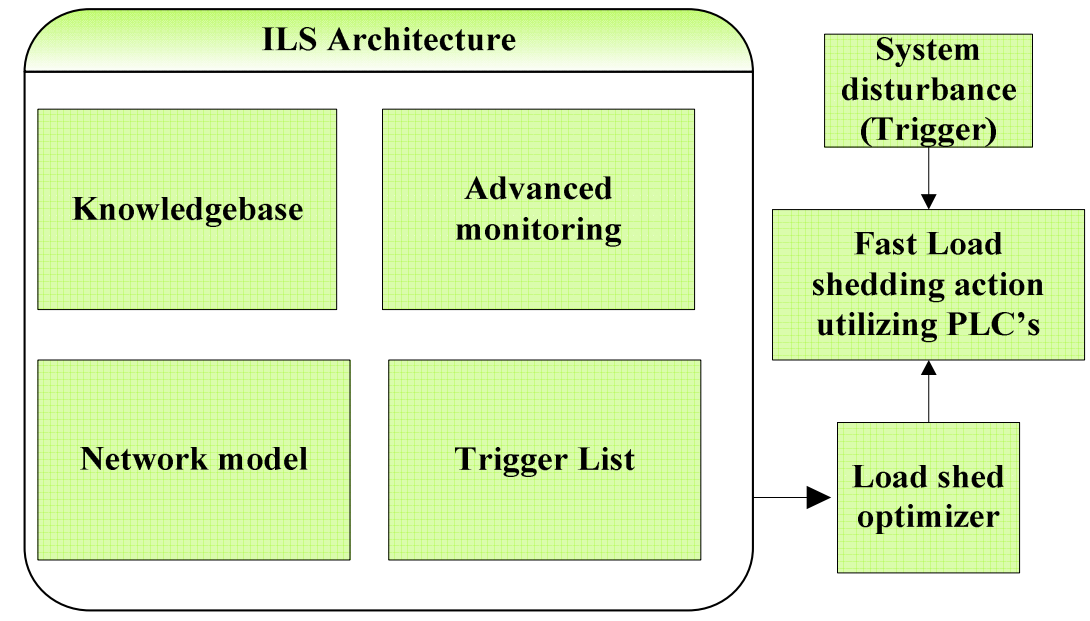

Figure 5. Functional blocks of computational intelligent load shedding scheme

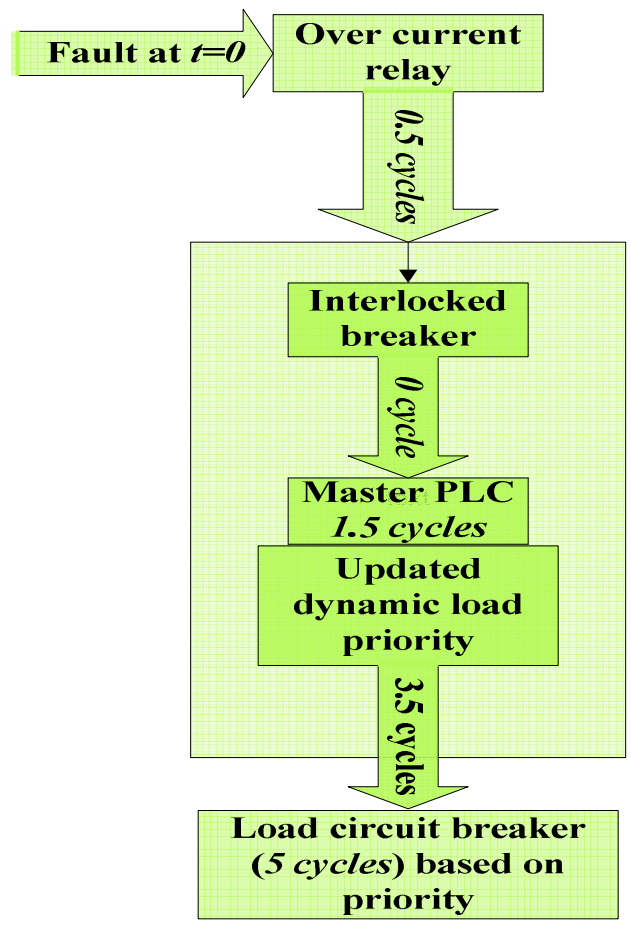

Figure 6. Load response time of computational intelligent LS

Scheme [16] incorporates Pre and post disturbance operating conditions, Nature, duration and System transient response to a disturbance. Techniques such as Neural Network (NN), Generic Algorithms (GA), Simulated Annealing (SA), Fuzzy Logic (FL) etc, offer effective problem solving, knowledge representation, planning and action, for highly non-linear problems. These techniques are user defined and minimum load shed are possible online. Figure 5. illustrates computational Intelligent Load Shedding scheme. Knowledgebase selects input/output data based on off-line system studies and simulations [16-17]. System operating conditions are surveyed through Advanced Monitoring. Network Models contain system topology. Based on compiled trigger list LS is executed which is fast and optimum. A computer simulation of an oil refinery 
electrical system was performed [16] to illustrate the benefits of applying an ILS scheme over a conventional PLC based scheme. It was observed that the total load response time is less about 7 cycles. Figure 6.

\subsubsection{Using Genetic Algorithm}

Genetic algorithms (GA) are based on the mechanics of natural selection and genetics. The basis is the Darwinian 'survival of the fittest' concept [23]. Load shedding method in the previous section [16] often causes over shedding as it involves the entire feeder for disconnection neglecting information about type of load connected to it. It is important to supply power to the right load at right time [22]. This section proposes a time priority based load shedding scheme using genetic algorithm in a smart grid field. Fig.7. describes the scheme. The objective function is the error between the required load shedding amount at substation and the actual [16, 22].

At the control centre, the load power consumption is obtained in real time and is fed as input to the algorithm, including the time of the day and the required amount of load shedding. Fig.8. shows a flow chart for GA based load shedding [23]. The solution obtained tries to supply the power to the consumer at its priority time. The algorithm provides Load shedding error within $0.5 \%[22]$.

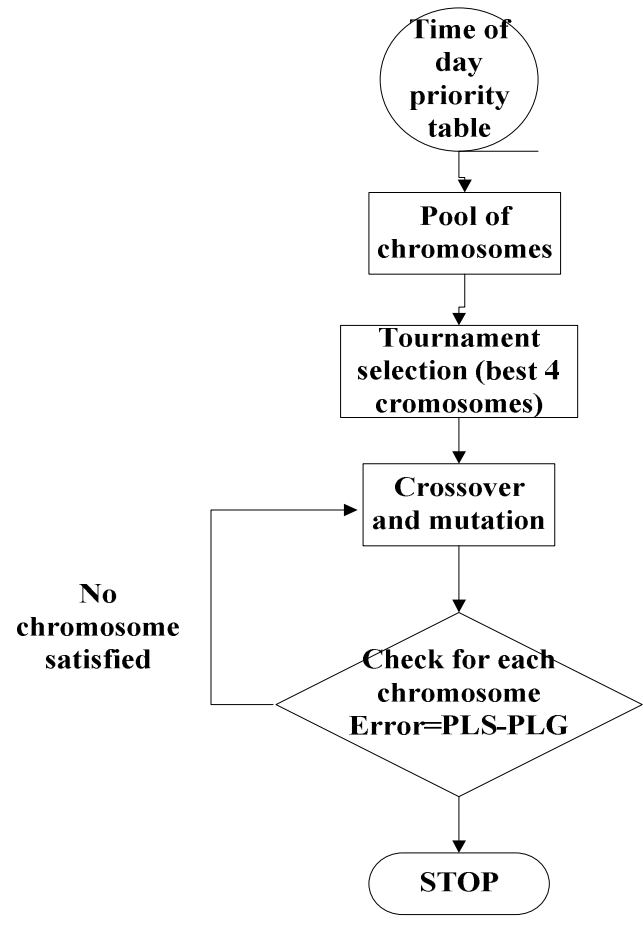

Fig.8 Flow chart for GA based load shedding

\subsubsection{Neural-Networks for Under-Frequency Load Shedding System}

The artificial neural-networks minimizes the computation time [18]. Each stage of the load shedding system has a time delay of its own. If frequency is recovered before the expiration of the time delay load shedding operation will not be executed [19]. The basic element of a neuralnetwork is the artificial neuron. After a thorough examination the following neural-network model was developed for minimal frequency [17]: 
- Each generating unit is represented by two input variables: the actual power and the available power along with spinning reserve.

- One neuron in output layer and a single hidden layer.

- Sigmoid transfer functions as the minimal frequency is a continuous variable.

- Full connectivity between the output and the hidden layers but Partial connectivity between the hidden and the input layers to decrease calculation times and maintain accuracy.

Each case in the data base specifies all the input variables as well as the output variable and contains real cases that occurred during previous years. The data base contains all kinds of forced outages of generating units [18]. The purpose of the neural-network is to predict which stages of the load shedding system would operate during a forced outage of a generating unit $[18,19]$.

\section{COMPARISON Of LOAD SHEDding SCHEMES}

A summary of different load shedding techniques compared together is described in Table 3.

Table 3. Comparision of load shedding schemes

\begin{tabular}{|c|c|c|}
\hline Conventional Load Shedding & Adaptive Load Shedding & $\begin{array}{l}\text { Computational Intelligent Load } \\
\text { Shedding }\end{array}$ \\
\hline $\begin{array}{l}\text { No account of system inertia } \\
\text { changes, or system topology [11, } \\
16] \text {. }\end{array}$ & $\begin{array}{l}\text { Includes System inertia constant } \\
\text { and other real time responses } \\
{[10,11] \text {. }}\end{array}$ & $\begin{array}{l}\text { Reflects true status and loading } \\
\text { conditions for the sheddable loads } \\
{[16] \text {. }}\end{array}$ \\
\hline $\begin{array}{l}\text { No communication between } \\
\text { remote protective relays and UF } \\
\text { appliances }[11,25] \text {. }\end{array}$ & $\begin{array}{l}\text { Fiber-optic communication, } \\
\text { satellite technology ect. Enable } \\
\text { fast data transmission }[10,11] \text {. }\end{array}$ & Scheme is user defined $[5,10]$. \\
\hline $\begin{array}{l}\text { Sheds fixed amount of load } \\
\text { based on threshold frequency. } \\
\text { Under/over shedding is seen [2, } \\
\text { 5]. }\end{array}$ & $\begin{array}{l}\text { Stepwise Loadshedding is done } \\
\text { depends on rate of change of } \\
\text { frequency decline. LS error } \\
\text { observed }[7,8] \text {. }\end{array}$ & $\begin{array}{l}\text { Minimum load shedding based on } \\
\text { real time status of sheddable loads. } \\
\text { LS error is minimized }[16,18] \text {. }\end{array}$ \\
\hline $\begin{array}{l}\text { Time delay included. Therefore a } \\
\text { slow response [5]. }\end{array}$ & $\begin{array}{l}\text { Includes time delay. Hence a } \\
\text { slow response [19]. }\end{array}$ & $\begin{array}{l}\text { Fast response with minimum time } \\
\text { delay [34]. }\end{array}$ \\
\hline $\begin{array}{l}\text { Based on most severe conditions } \\
\text { [35]. }\end{array}$ & $\begin{array}{l}\text { Depends on instantaneous } \\
\text { frequency decay rate }[21,34] .\end{array}$ & $\begin{array}{l}\text { Based on system dynamic } \\
\text { characteristics on real time }[19, \\
21] .\end{array}$ \\
\hline $\begin{array}{l}\text { Complex design with large } \\
\text { number of I/O relays }[11,26] .\end{array}$ & $\begin{array}{l}\text { Decreased complexity increased } \\
\text { reliability [11]. }\end{array}$ & Decreased complexity [34]. \\
\hline $\begin{array}{l}\text { Load priority list not properly } \\
\text { classified [38]. }\end{array}$ & $\begin{array}{l}\text { It may happen that power is } \\
\text { supplied to non-critical loads } \\
\text { [44]. }\end{array}$ & $\begin{array}{l}\text { The load shedding priority list is } \\
\text { updated and sub-categorized in } \\
\text { critical and non-critical loads [7, } \\
\text { 11]. }\end{array}$ \\
\hline $\begin{array}{l}\text { Large simulation and transient } \\
\text { stability studies required }[16, \\
35] .\end{array}$ & $\begin{array}{l}\text { Large simulation studies not } \\
\text { required }[10,12] .\end{array}$ & $\begin{array}{l}\text { Large simulation studies not } \\
\text { required [44]. }\end{array}$ \\
\hline
\end{tabular}

\section{CONClusion}

In an interconnected power system huge gap between power generation and demand is seen. Reliable techniques are required for fast and accurate load shedding. Factors affecting underfrequency conditions and the consequent effect on system equipments which can damage the entire network have been discussed. The conventional schemes shed fixed amount of load blocks which may cause insufficient load shedding. Adaptive methods take into account the rate 
of change of frequency and load shedding is done based on a simple formulae. Due to inherent disadvantages in conventional and adaptive methods Computational intelligence techniques are required. This paper has presented a review of conventional, adaptive and computational intelligence techniques in load shedding and discussed the relative merits and demerits. It can be concluded that computational intelligence techniques in load shedding are more efficient than other methods with respect to fast response, exact load shedding amount and updated load priority list. However, further improvements are still needed. A summary of full comparison of load shedding methods is presented.

\section{REFERENCES}

[1] M. Giroletti; M. Farina; R. Scattolini, “A hybrid frequency/power based method for industrial load shedding" Electrical Power and Energy Systems 35 (2012) 194-200.

Delfino, B.; Massucco, S.; Morini, A.; Scalera, P.; Silvestro, F., "Implementation and comparison of different under frequency load-shedding schemes," Power Engineering Society Summer Meeting, 2001 , vol.1, no., pp.307,312 vol.1, 2001

[2] Paolo Pinceti," Emergency load-shedding algorithm for large industrial plants," Control Engineering Practice 10 (2002) 175-181

[3] Yu-Lung Ke; Chen-Ting Hsu; Chao-Shun Chen, "Protective relay setting of the tie line tripping and load shedding for the industrial power system," Industrial \& Commercial Power Systems Technical Conference, 1999 IEEE. , vol., no., pp.7 pp.,, Aug 1999

[4] Khaki, B.; Kouhsari, S.M., "Proper setting of underfrequency load shedding relays in industrial plants," Environment and Electrical Engineering (EEEIC), 2010 9th International Conference on , vol., no., pp.198,201, 16-19 May 2010

[5] Bevrani, H.; Ledwich, G.; Ford, J.J., "On the use of df/dt in power system emergency control," Power Systems Conference and Exposition, 2009. PSCE '09. IEEE/PES , vol., no., pp.1,6, 15-18 March 2009

[6] Rudez, U.; Mihalic, R., "Analysis of Underfrequency Load Shedding Using a Frequency Gradient," Power Delivery, IEEE Transactions on , vol.26, no.2, pp.565,575, April 2011

[7] Parniani, M.; Nasri, A., "SCADA based under frequency load shedding integrated with rate of frequency decline," Power Engineering Society General Meeting, 2006. IEEE , vol., no., pp.6 pp.,, 0-

[8] Chen, C-S; Lee, Y.D.; Hsu, C.T.; Chuang, H. -J, "Design of Undervoltage Relay Setting for an Industrial Plant With Cogeneration Units to Enhance Power Quality of Critical Loads," Industry Applications, IEEE Transactions on , vol.44, no.4, pp.1295,1302, July-aug. 2008

[9] Terzija, V.V., "Adaptive underfrequency load shedding based on the magnitude of the disturbance estimation," Power Systems, IEEE Transactions on, vol.21, no.3, pp.1260,1266, Aug. 2006

[10] Manson, S.; Zweigle, G.; Yedidi, V., "Case study: An adaptive underfrequency load-shedding system," Petroleum and Chemical Industry Technical Conference (PCIC), 2013 Record of Conference Papers Industry Applications Society 60th Annual IEEE, vol., no., pp.1,9, 23-25 Sept. 2013

[11] U. Rudez, V. Azbe, and R. Mihalic, "The application of a frequency gradient for underfrequency load shedding," Electrotech. Rev., vol. 75, no. 3, 2008.

[12] Jethwa, U.K.; Bansal, R.K.; Date, N.; Vaishnav, R., "Comprehensive Load-Shedding System," Industry Applications, IEEE Transactions on , vol.46, no.2, pp.740,749, March-april 2010

[13] Kalam, A.; Chakrabarti, J.; Muttucumaru, R., "A genetic algorithm approach for load shedding in an industrial cogeneration power plant," Industrial Electronics, Control, and Instrumentation, 1996., Proceedings of the 1996 IEEE IECON 22nd International Conference on , vol.2, no., pp.848,851 vol.2, 5-10 Aug 1996

[14] Rajamani, K.; Hambarde, U.K., "Islanding and load shedding schemes for captive power plants," Power Engineering Society 1999

[15] Winter Meeting, IEEE , vol.2, no., pp.966 vol.2, 31 Jan-4 Feb 1999 Shervin Shokooh; Tanuj Khandelwal; Dr. Farrokh Shokooh; Jacques Tastet; Dr. JJ Dai, “ Intelligent Load Shedding Need for a Fast and Optimal Solution," IEEE PCIC Europe 2005

[16] Kottick, D.; Or, O., "Neural-networks for predicting the operation of an under-frequency load shedding system," Power Systems, IEEE Transactions on , vol.11, no.3, pp.1350,1358, Aug 1996

[17] Aggoune, M.; El-Sharkawa, M.A.; Park, D.C.; Damborg, M.J.; Marks, R.J., II, "Preliminary results on using artificial neural networks for security assessment [of power systems]," Power Systems, IEEE Transactions on , vol.6, no.2, pp.890,896, May 1991

[18] Anderson, P.M.; Mirheydar, M., "A low-order system frequency response model," Power Systems, IEEE Transactions on, vol.5, no.3, pp.720,729, Aug 1990

[19] Nirenberg, S.A.; McInnis, D.A.; Sparks, K.D., "Fast acting load shedding," Power Systems, IEEE Transactions on, vol.7, no.2, pp.873,877, May 1992

[20] P. Kundur, Power system stability and control, McGraw Hill, 1994. 
[21] Rao, K.U.; Bhat, S.H.; Jayaprakash, G.; Ganeshprasad, G.G.; Pillappa, S.N., "Time priority based optimal load shedding using genetic algorithm," Communication and Computing (ARTCom 2013), Fifth International Conference on Advances in Recent Technologies in , vol., no., pp.301,308, 20-21 Sept. 2013

[22] David E Goldberg, Genetic Algorithm, Pearson education publication, 2009.

[23] Hassan Bevrani; Gerard Ledwich; Zhao Yang Dong; Jason J. Ford,"Regional frequency response analysis under normal and emergency conditions" Electric Power Systems Research 79 (2009) 837 845

[24] Peter E. Sutherland; Vinicius Roubach; Leandro Matos Riani," Stability requirements in a steel mill" IEEE INDUSTRY APPLICATIONS MAGAZINE SEPT - OCT 2010

[25] Farrokh Shokooh; J.J. Dai; Shervin Shokooh; Hugo Castro; Tanuj Khandelwal; Gary Donner," Intelligent Load Shedding Case study of the application in a large industrial facility" IEEE INDUSTRY APPLICATIONS MAGAZINE MAR-APR 2011

[26] Halevi, Y.; Kottick, D., "Optimization of load shedding system," Energy Conversion, IEEE Transactions on , vol.8, no.2, pp.207,213, Jun 1993

[27] D. Prasetijo,W. R. Lachs, and D. Sutanto, “A newload shedding for limiting underfrequency,” IEEE Trans. Power Syst., vol. 9, pp. 1371-1378, Aug. 1994.

[28] P. M. Anderson and M. Mirheydar, "An adaptive method for setting underfrequency load shedding relays,” IEEE Trans. Power Syst., vol. 7, pp. 647-655, May 1992.

[29] Concordia, C.; Fink, L.H.; Poullikkas, G., "Load shedding on an isolated system," Power Systems, IEEE Transactions on, vol.10, no.3, pp.1467,1472, Aug 1995

[30] Le-Ren Chang-Chien; Luu Ngoc An; Ta-Wei Lin; Wei-Jen Lee, "Incorporating Demand Response With Spinning Reserve to Realize an Adaptive Frequency Restoration Plan for System Contingencies," Smart Grid, IEEE Transactions on , vol.3, no.3, pp.1145,1153, Sept. 2012

[31] You, H.; Vittal, V.; Zhong Yang, "Self-healing in power systems: an approach using islanding and rate of frequency decline-based load shedding," Power Systems, IEEE Transactions on , vol.18, no.1, pp.174,181, Feb 2003

[32] Prasetijo, D.; Lachs, W.R.; Sutanto, D., "A new load shedding scheme for limiting underfrequency," Power Systems, IEEE Transactions on , vol.9, no.3, pp.1371,1378, Aug 1994

[33] P.M. Anderson, Power System Protection, IEEE Press Series on Power Engineering, Vol,4, Wiley, 1998

[34] C. T. Hsu, C. S. Chen, and J. K. Chen, "The load shedding scheme design for an integrated steelmaking cogeneration facility," IEEE Trans. Ind. Appl., vol. 33, no. 3, pp. 586-592, May/Jun. 1997.

[35] Jones, J.R.; Kirkland, W.D., "Computer algorithm for selection of frequency relays for load shedding," Computer Applications in Power, IEEE , vol.1, no.1, pp.21,25, Jan. 1988

[36] Lokay, H.E.; Burtnyk, V., "Application of Underfrequency Relays for Automatic Load Shedding," Power Apparatus and Systems, IEEE Transactions on, vol.PAS-87, no.3, pp.776,783, March 1968

[37] M. H. J. Bollen, Understanding Power Quality Problems: Voltage Sags and Interruptions. New York: IEEE Press, 2000.

[38] C. T. Hsu, "Cogeneration system design for a high-tech science-based industrial park," IEEE Trans. Ind. Appl., vol. 39, no. 5, pp. 1486-1492, Sep./Oct. 2003.

[39] J. C. Das, "Transient stability of small plant generators connected to a weak utility system-A case study," IEEE Trans. Ind. Appl., vol. 41, no. 1, pp. 155-162, Jan./Feb. 2005.

[40] V. N. Chuvychin, N. S. Gurov, S. S. Venkata, and R. E. Brown, "An adaptive approach to load shedding and spinning reserve control during underfrequency conditions," IEEE Trans. Power Syst., vol. 11, no. 4, pp. 1805-1810, Nov. 1996.

[41] Sutherland, P.E.; Roubach, V.; Riani, L.M., "Stability Requirements for Implementation of Grid Separation Scheme in a Steel Mill with Internal Generation," Industry Applications Society Annual Meeting, 2008. IAS '08. IEEE, vol., no., pp.1,7, 5-9 Oct. 2008

[42] John P. Fievet, "The use of programmable logic controllers in paper mill load shed systems," TAPPI Journal, Vol. 80, No. 3, March 1997

[43] Qingsheng Zhao, Chen Chen," Study on a system frequency response model for a large industrial area load shedding” Electrical Power and Energy Systems 27 (2005) 233-237

\section{AUTHORS}

Pradeepti Lakra received the B.Tech. degree (2012) in Electrical Engineering from Maulana Azad National Institute of Technology, Bhopal, India. Presently she is persuiing Masters of Technology from Maulana Azad National Institute of Technology, Bhopal, India, from 2013-2015. Her area of specialization in Power system Engineering.

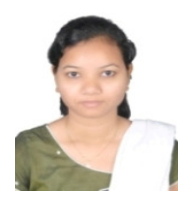

Mukesh Kumar Kirar received the PhD from Maulana Azad National Institute of Technology, Bhopal, India. He is presently working as assistant professor in M.A.N.I.T. Bhopal. 